\title{
The Spread of Nezara viridula (Hemiptera:Pentatomidae) Species from its First Occurrence in Romania
}

\author{
Ioana GROZEA*, Ana Maria VIRTEIU, Ramona STEF, Alin CARABET, Levente MOLNAR, Viorela MARCU, \\ Diana DRAGA
}

Department of Biology and Plant Protection, Banat's University of Agricultural Sciences and Veterinary Medicine "King Michael I of Romania" Timisoara, Romania;

*)Corresponding author, e-mail: ioana_entomol@yahoo.com

BulletinUASVM Horticulture 73(2) / 2016

Print ISSN 1843-5254, Electronic ISSN 1843-5394

DOI:10.15835/buasvmcn-hort:12128

\begin{abstract}
Lately in horticultural agroecosystems from Romania several autochthonous insect species have joined. Among these, is a species of bugs known as southern green stink bugs or Nezara viridula L. (Insecta: Hemiptera: Pentatomidae). Unlike other new entrants this bug species has a diversified polifagism being present in many plants but obvious damage produce only in tomato fruit. The causes are unknown; it can be found in gardens, green spaces and parks. Often can be observed in vegetable gardens where populations comprise all stages (egg, larva/ nymph, adult). Although it has African origins of a warm area the installation and survival conditions are similar to those from Europe. Its presence in Europe seems to be random which excludes the primarily spread through the neighborhood. The observations that have been made during this research in the western part of Romania between 2010-2015, were focused on the evolution of the insect from the first point of occurrence (Timișoara, 2010). Also, tomato crops and ornamentals were monitored in gardens and green spaces from 5 counties; only in four counties was this species observed. Most of the adults and larvae were registered in Timis county (5-6 adults or 7-8 larvae/tomato plant and 10 -11 adults or 15-20 larvae/ornamental shrub). In our country the insect has proven to be capable of a rapid spread in a relatively short time interval including surrounding counties.
\end{abstract}

Keywords: emergence, first point, Nezara viridula, spread

\section{Introduction}

Nezara viridula (Linnaeus) commonly known as the green stink bug or southern green stink bug is the last acquisition of Romania if we refer to the insect species. An important aspect about this species is that it was recognized as polyphagous and has been recorded feeding on a wide range of monocotyledonous and dicotyledonous plants, especially on legumes (Velasco and Walter, 1992). Its origins from Africa (Jones, 1988) and its development from the Mediterranean area (somewhat neighbouring our continent) were an explanation for the installation and subsequent of the species in Europe (CABI/ORG, 2016; Collazza et al., 1996).

\section{Aims and objectives}

Considering that this insect is a relatively new entry into the country it is important to monitor its activity every year and the new areas where this species occur. In this context this paper highlights the green stink bug occurence from a verly early stage of spread (Timisoara, Romania).

\section{Materials and methods}

Monitoring the species Nezara viridula was the main aim of this work. In order to do this, spread maps were used to identify the places where this species first occure in Romania (Timisoara: Timis County). This species was discovered for the first time in our country 6 years ago (in 2010), in a 


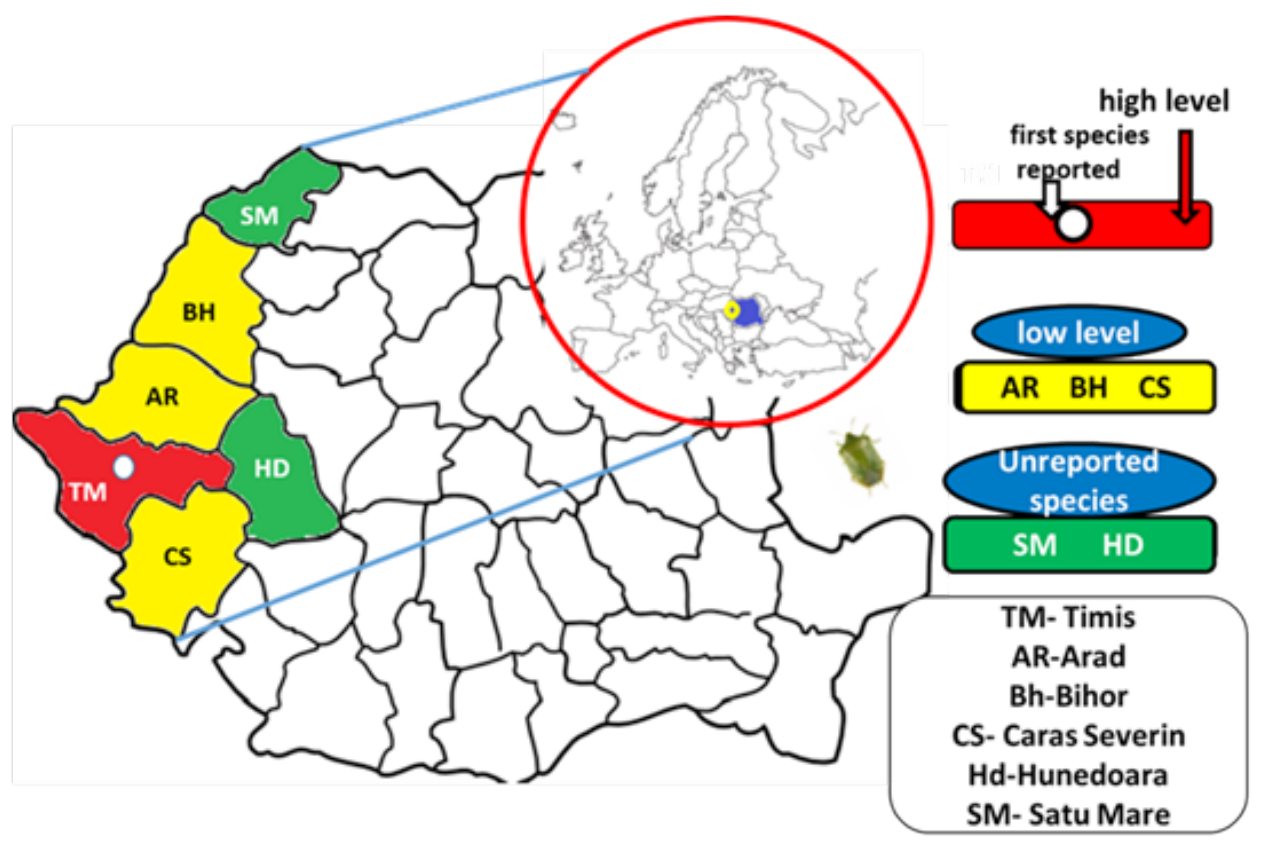

Fig 1. The spread of Nezara viridula species in Romania, from the first occurence
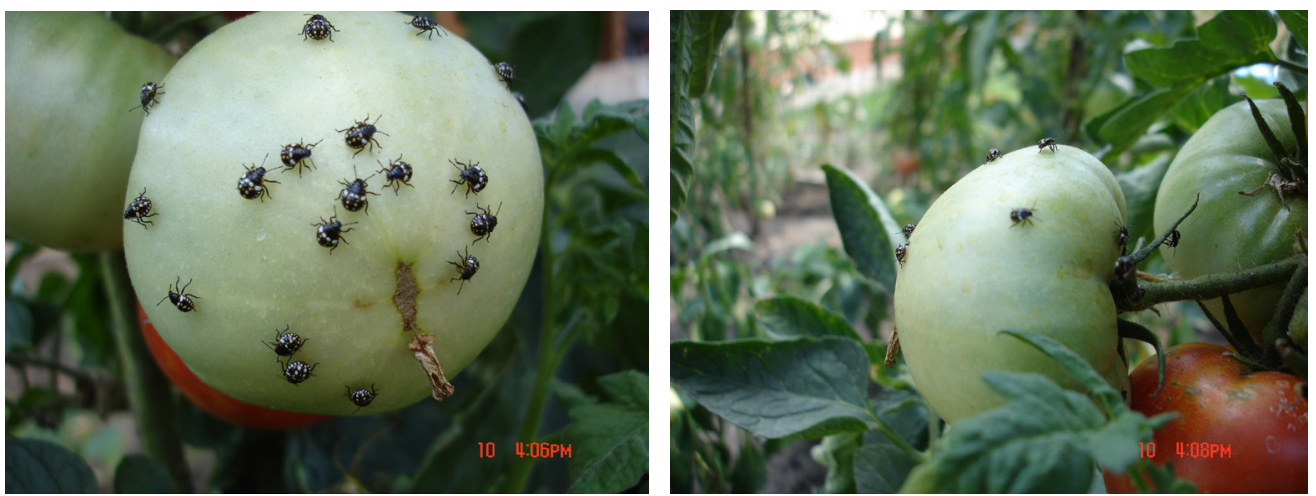

Fig 2. Larvae population of the Nezara viridula on tomato. Source: original

tomato culture (Grozea et al., 2012). The area subjected to monitoring included six neighboring counties (Timis-TM, Arad-AR, Caras-Severin-CS, Bihor-BH, Satu Mare-SM and Hunedoara-HD). The research period was 5 years (2010-2015) for TM and 3 years for other counties. The observations were made mainly in tomatoes and green spaces, in 3 different points of each county.

Results and Discussion. The result show that in four out of the six monitored countries the occurrence of this pest was observed (Fig. 1). In Timis county, the insect's populations were present on a high level (5-6 adults or 7-8 larvae/tomato plant (Fig. 2) or 10-11 adults or 15-20 larvae/ ornamental shrub). Low values were recorded in the following counties: Arad, Bihor and CarașSeverin. Most of the locations where observations have been made, were marked by low levels as follows: $0.5-1$ adults or 1-3 larvae/tomato plant or 1-3 adults or 3-4 larvae/ornamental shrub. In two from the monitored counties (Satu Mare and Hunedoara) no stink bug occurrence was observed.

\section{Conclusion}

The rapid spread in 5 years after the first occurrence of this species in Romania indicate that the green stink bug is a strong flier and is capable for long-distance spread. 


\section{REFERENCES}

1. Grozea I, Ştef R., Vîrteiu AM, Cărăbeț, A and Molnar L (2012). Southern green stink bugs (Nezara viridula L.) a new pest of tomato crops in western Romania. Res. J. Agric. Sci. 44 (2): 24-28.

2. Velasco LRI and Walter GH (1992). Availability of different host plant species and hanging abundance of the polyphagous bug Nezara viridula (Hemiptera: Pentatomidae). Environm. Entomol. 21(4): 751- 759.
3. CABI/ORG (2016). Invasive Species Compendium, Nezara viridula, green stink bug. Distribution map (www.org. cabi).

4. Colazza S, Giangiuliani G and Bin F (1996). Fortuitous introduction and successful establishment of Trichopoda pennipes F. adult parasitoids of Nezara viridula (L.). Biol. Contr. 6(3): 409-411. 